\title{
Nebulised surfactant in preterm infants with or at risk of respiratory distress syndrome (Review)
}

\author{
Abdel-Latif ME, Osborn DA
}

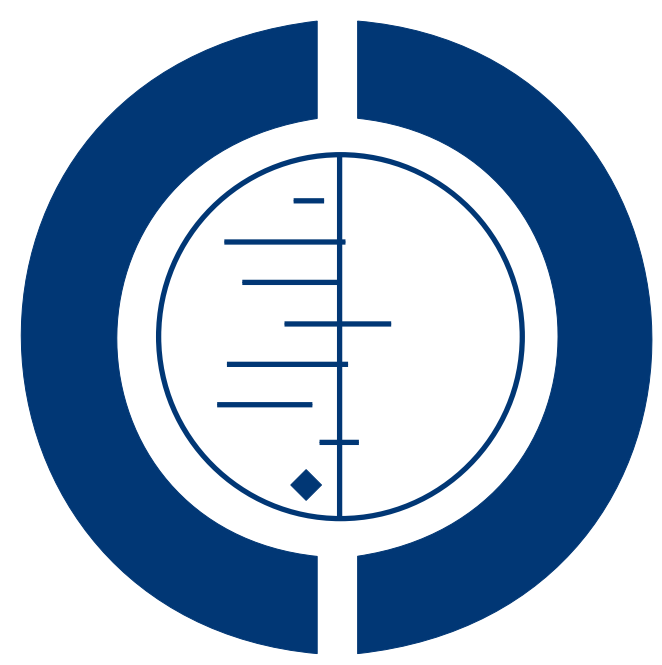

\section{THE COCHRANE COLLABORATION $^{\circledR}$}

This is a reprint of a Cochrane review, prepared and maintained by The Cochrane Collaboration and published in The Cochrane Library 2012, Issue 10

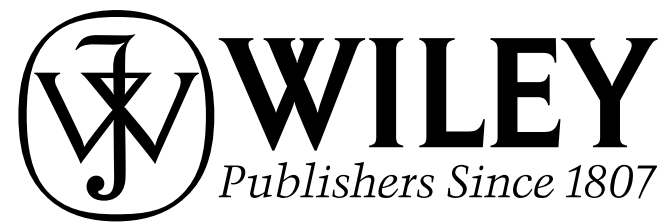

Nebulised surfactant in preterm infants with or at risk of respiratory distress syndrome (Review)

Copyright $\odot 2012$ The Cochrane Collaboration. Published by John Wiley \& Sons, Ltd. 
TABLE OF CONTENTS

HEADER . . . . . . . . . . . . . . . . . . . . . . . . . . . . . . . . . . . . 1

ABSTRACT . . . . . . . . . . . . . . . . . . . . . . . . . . . . . . . . . . . . . . . . 1

PLAIN LANGUAGE SUMMARY . . . . . . . . . . . . . . . . . . . . . . . . . . . . . . . . . . . . 2

BACKGROUND . . . . . . . . . . . . . . . . . . . . . . . . . . . . . . . . . . . . . .

OBJECTIVES . . . . . . . . . . . . . . . . . . . . . . . . . . . . . . . . . . . . . . . . . . . . .

METHODS . . . . . . . . . . . . . . . . . . . . . . . . . . . . . . . . . . . . . . . . .

RESULTS . . . . . . . . . . . . . . . . . . . . . . . . . . . . . . . . . . . . . . . 8

DISCUSSION . . . . . . . . . . . . . . . . . . . . . . . . . . . . . . . . . . . . . 9

AUTHORS' CONCLUSIONS . . . . . . . . . . . . . . . . . . . . . . . . . . . . . . . . . . . . 10

ACKNOWLEDGEMENTS . . . . . . . . . . . . . . . . . . . . . . . . . . . . . . . . . 10

REFERENCES . . . . . . . . . . . . . . . . . . . . . . . . . . . . . . . . . . . . . . 11

CHARACTERISTICS OF STUDIES . . . . . . . . . . . . . . . . . . . . . . . . . . . . . . . . . . . . .

DATA AND ANALYSES . . . . . . . . . . . . . . . . . . . . . . . . . . . . . . . . . . . . . . . . . . . . . . . . . .

Analysis 1.1. Comparison 1 Treatment of RDS with nebulised surfactant versus no treatment, Outcome 1 Chronic lung disease. . . . . . . . . . . . . . . . . . . . . . . . . . . . . . . . . . . . . 18

Analysis 1.2. Comparison 1 Treatment of RDS with nebulised surfactant versus no treatment, Outcome 2 Mechanical ventilation. . . . . . . . . . . . . . . . . . . . . . . . . . . . . . . . . . . . 19

Analysis 1.3. Comparison 1 Treatment of RDS with nebulised surfactant versus no treatment, Outcome 3 Air leak. . 19

Analysis 1.4. Comparison 1 Treatment of RDS with nebulised surfactant versus no treatment, Outcome 4 Patent ductus arteriosus. . . . . . . . . . . . . . . . . . . . . . . . . . . . . . . . . . . . 20

Analysis 1.5. Comparison 1 Treatment of RDS with nebulised surfactant versus no treatment, Outcome 5 Pathological cerebral ultrasound at 1 week. . . . . . . . . . . . . . . . . . . . . . . . . . . . . 20

APPENDICES . . . . . . . . . . . . . . . . . . . . . . . . . . . . . . . . . . . 20

HISTORY . . . . . . . . . . . . . . . . . . . . . . . . . . . . . . . . . . . . . . . . . . .

CONTRIBUTIONS OF AUTHORS . . . . . . . . . . . . . . . . . . . . . . . . . . . . . . . . . . . . . . . . . .

DECLARATIONS OF INTEREST . . . . . . . . . . . . . . . . . . . . . . . . . . . . . . . . . . . . . . . . .

SOURCES OF SUPPORT . . . . . . . . . . . . . . . . . . . . . . . . . . . . . . . . . . . . . . . . . . . . . . . . . .

DIFFERENCES BETWEEN PROTOCOL AND REVIEW . . . . . . . . . . . . . . . . . . . . . . 22

INDEX TERMS . . . . . . . . . . . . . . . . . . . . . . . . . . . . . . . . . . . . . 22

Nebulised surfactant in preterm infants with or at risk of respiratory distress syndrome (Review)

Copyright $\odot 2012$ The Cochrane Collaboration. Published by John Wiley \& Sons, Ltd. 


\title{
[Intervention Review] \\ Nebulised surfactant in preterm infants with or at risk of respiratory distress syndrome
}

\author{
Mohamed E Abdel-Latif ${ }^{1}$, David A Osborn ${ }^{2}$ \\ ${ }^{1}$ Department of Neonatology, Australian National University Medical School, Woden, Australia. ${ }^{2}$ Central Clinical School, Discipline \\ of Obstetrics, Gynaecology and Neonatology, University of Sydney, Sydney, Australia \\ Contact address: Mohamed E Abdel-Latif, Department of Neonatology, Australian National University Medical School, PO Box 11, \\ Woden, ACT, 2606, Australia. Abdel-Latif.Mohamed@act.gov.au. \\ Editorial group: Cochrane Neonatal Group. \\ Publication status and date: New, published in Issue 10, 2012. \\ Review content assessed as up-to-date: 27 January 2012.
}

Citation: Abdel-Latif ME, Osborn DA. Nebulised surfactant in preterm infants with or at risk of respiratory distress syndrome. Cochrane Database of Systematic Reviews 2012, Issue 10. Art. No.: CD008310. DOI: 10.1002/14651858.CD008310.pub2.

Copyright (C) 2012 The Cochrane Collaboration. Published by John Wiley \& Sons, Ltd.

\begin{abstract}
A B S T R A C T
Background

Nebulised surfactant has the potential to deliver surfactant to the infant lung with the goal of avoiding endotracheal intubation and ventilation, ventilator-induced lung injury and bronchopulmonary dysplasia (BPD).
\end{abstract}

\section{Objectives}

To determine the effect of nebulised surfactant administration either as prophylaxis or treatment compared to placebo, no treatment or intratracheal surfactant administration on morbidity and mortality in preterm infants with, or at risk of, respiratory distress syndrome (RDS).

\section{Search methods}

Searches were performed of CENTRAL (The Cochrane Library, January 2012), MEDLINE and PREMEDLINE (1950 to January 2012), EMBASE (1980 to January 2012) and CINAHL (1982 to January 2012), as well as proceedings of scientific meetings, clinical trial registries, Google Scholar and reference lists of identified studies. Expert informants and surfactant manufacturers were contacted.

\section{Selection criteria}

Randomised, cluster-randomised or quasi-randomised controlled trials of nebulised surfactant administration compared to placebo, no treatment, or other routes of administration (laryngeal, pharyngeal instillation of surfactant before the first breath, thin endotracheal catheter surfactant administration or intratracheal surfactant instillation) on morbidity and mortality in preterm infants at risk of RDS. We considered published, unpublished and ongoing trials.

\section{Data collection and analysis}

Two review authors independently assessed studies for eligibility and quality, and extracted data.

\section{Main results}

No studies of prophylactic or early nebulised surfactant administration were found. A single small study of late rescue nebulised surfactant was included. The study is of moderate risk of bias. The study enrolled 32 preterm infants born < 36 weeks' gestation with RDS on nasal continuous positive airway pressure (nCPAP). The study reported no significant difference between nebulised surfactant

Nebulised surfactant in preterm infants with or at risk of respiratory distress syndrome (Review)

Copyright $\odot 2012$ The Cochrane Collaboration. Published by John Wiley \& Sons, Ltd. 
administration compared to no treatment groups in chronic lung disease (risk ratio (RR) 5.00; 95\% confidence interval (CI) 0.26 to 96.59) or other outcomes (oxygenation 1 to 12 hours after randomisation, need for mechanical ventilation, days of mechanical ventilation or continuous positive airways pressure (CPAP) or days of supplemental oxygen). No side effects of the nebulised surfactant therapy or aerosol inhalation were reported.

\section{Authors' conclusions}

There are insufficient data to support or refute the use of nebulised surfactant in clinical practice. Adequately powered trials are required to determine the effect of nebulised surfactant administration for prevention or early treatment of RDS in preterm infants. Nebulised surfactant administration should be limited to clinical trials.

\section{PLAIN LANGUAGE SUMMARY}

\section{Nebulised surfactant in preterm infants with or at risk of respiratory distress syndrome}

There is insufficient evidence from randomised controlled trials to guide the use of nebulised surfactant in preterm infants at risk of respiratory distress syndrome.

Respiratory distress syndrome is caused by a deficiency of the naturally occurring lining chemicals of the lung (surfactant) and occurs mainly in infants born before term (37 weeks' gestation). Usual treatment includes instilling artificial surfactant directly into the newborn infant's trachea followed by mechanical ventilation. However, this process can lead to lung injury, which can affect the infant's long-term health. A potential alternative strategy is to use nebulised surfactant. This procedure has the potential to reduce the need for tracheal intubation after birth and subsequent lung damage caused by mechanical ventilation. This review found one small randomised controlled trial of nebulised surfactant administration in preterm infants with respiratory distress syndrome that reported no beneficial effect of nebulised surfactant. This study is too small and has a moderate risk of bias making conclusions uncertain. In view of the encouraging results from other observational studies, high-quality trials of nebulised surfactant in preterm infants with or at risk of respiratory distress syndrome are justified.

\section{B A C K G ROU N D}

\section{Description of the condition}

Respiratory distress syndrome (RDS) results from pulmonary surfactant deficiency and is an important cause of morbidity and mortality in preterm infants. Randomised controlled trials (RCTs) and meta-analyses have demonstrated the efficacy of surfactant therapy in both prevention and treatment of infants with or at risk for RDS. A wide variety of surfactant preparations have been studied. These include synthetic surfactants (Soll 2000; Soll 2010) and surfactants derived from animal sources (natural surfactants) (Soll 1997; Seger 2009). Although both synthetic and animal-derived surfactant preparations are effective, clinical trials suggest that animal-derived surfactant preparations (Soll 2001) may be more effective than protein-free synthetic surfactant (Tooley 1987). Furthermore, clinical trials have shown earlier treatment may be superior to selective use of surfactant in preventing morbidity and mortality in preterm infants (Yost 2000; Stevens 2007; Rojas-Reyes
2012), and a multiple-dose is superior to a single-dose strategy (Soll 2009). New protein-containing synthetic surfactants have been successfully tested (Pfister 2007; Pfister 2009) although these preparations are not currently available for clinical use. Despite the benefits of surfactant, many infants develop bronchopulmonary dysplasia (BPD) and chronic lung disease (CLD). Although the aetiology of CLD in preterm infants is multifactorial (Allen 2003), ventilator-induced lung injury (VILI) remains one of the main implicated risk factors (Coalson 1999; Clark 2000). VILI has been shown to start with only a few resuscitative positive pressure ventilation (PPV) breaths (Grossmann 1986; Björklund 1997; Flecknoe 2008; O’Reilly 2008).

Both surfactant prophylaxis and therapy necessitate endotracheal intubation to facilitate surfactant administration. Although surfactant by itself is an established effective intervention for either prevention or treatment of RDS, the endotracheal intubation and PPV that follow are not without side effects.

Endotracheal intubation is a potentially traumatic procedure often performed without optimal pain management (Sarkar 2006). 
It may be accompanied by significant haemodynamic instability including hypoxia, bradycardia, blood pressure fluctuation and intracranial pressure increase (Marshall 1984; Ghanta 2007). Intubation is inevitably associated with colonisation of the trachea, retained secretions resulting in collapse, differential aeration and high resistance to air flow resulting in increased work of breathing, potentially leading to nosocomial pneumonia and sepsis (Young 2005; Aly 2008). Intubation is associated with an inflammatory process that can lead to lung injury and BPD (Young 2005). Current evidence suggests PPV of an immature, surfactant-deficient lung is harmful and may exacerbate the development of BPD (Björklund 1997; Van Marter 2000). Björklund 1997 reported resuscitation of surfactant-deficient immature lambs with as few as six breaths damages the lung and blunts the therapeutic effect of subsequent surfactant replacement. Grossmann 1986 reported similar results. Flecknoe 2008 reported that just six hours of ventilation is enough to cause marked airway epithelial injury in very preterm and near-term foetal sheep. O'Reilly 2008 reported that ventilator-induced injury extends to involve the conducting airways as well.

One approach for surfactant administration is the InSurE (INtubation-SURfactant-Extubation) technique pioneered by Victorin and Verder (Verder 1994; Victorin 1990). Review of trials found early surfactant replacement therapy with prompt extubation to nasal continuous positive airway pressure (nCPAP), as in the InSurE technique, is associated with less need for mechanical ventilation, lower incidence of BPD and fewer air leak syndromes when compared with later selective surfactant replacement and continued mechanical ventilation with extubation from low ventilator support (Stevens 2007). However, the limited data available show the InSurE procedure to be associated with a trend for decreased cerebral oxygenation, higher cerebral oxygen extraction and decreased electric brain activity (Hellstrom-Westas 1992; van de Berg 2009). Furthermore, the InSurE procedure may need to be repeated if the first dose of surfactant was not sufficiently effective (Bohlin 2007), leading to additional risk of brain damage. The main strategy used to avoid endotracheal intubation and PPV in premature infants is application of nCPAP or continuous distending pressure (CDP) immediately following birth (Kamper 1999; Ho 2002a; Ho 2002b). Some studies suggest CDP may lead to less CLD compared to elective intubation, surfactant and PPV (Aly 2001; DeKlerk 2001; SUPPORT Study Group 2010; Dunn 2011). Similarly, nasal intermittent positive pressure ventilation (NIPPV) has been shown to increase the likelihood of avoiding intubation and mechanical ventilation, reduce frequency of apnoea and a trend for less CLD without an increase in adverse effects (Lemyre 2002; Davis 2008). Although CDP and NIPPV strategies avoid endotracheal intubation and PPV, it precludes surfactant administration, which is a standard and confirmed treatment for RDS. Furthermore, CDP, NIPPV and InSurE may fail in 25\% to $50 \%$ of preterm infants (Reininger 2005; Kugelman 2007; Morley 2008).

\section{Description of the intervention}

Non-invasive methods of surfactant administration have the potential to reduce the need for intubation and endotracheal surfactant administration. Potential strategies include:

1. intra-amniotic instillation (Petrikovsky 1995);

2. pharyngeal instillation (Kattwinkel 2004);

3. administration via laryngeal mask airway surfactant

(Trevisanuto 2005);

4. administration via thin endotracheal catheter without intermittent positive pressure ventilation (IPPV) (Kribs 2007; Kribs 2010; Dargaville 2011);

5. nebulised surfactant administration in spontaneously breathing infants (Jorch 1997).

This review will focus on nebulised surfactant administration. The typical protocol for nebulised surfactant administration (Finer 2006) involves using an aerosol generator with nebulised surfactant administered via a nCPAP system, tight face-mask system or nasopharyngeal tube. Aerosol generators include jet nebulisers, ultrasonic nebulisers and vibrating membrane nebulisers. There is an aerosolised form of peptide-containing surfactant available but other forms of surfactant have also been tried.

In preterm animal models and animal models of induced lung injury, nebulised surfactant improved ventilation and lung mechanics, even with minimal deposition in the lungs (Lewis 1991; Lewis 1993a; Lewis 1993b; Lewis 1993c; Wolfson 2008). Johnson 2006 and Johnson 2007 measured surface activity of aerosolised lucinactant in vitro (using a pulsating bubble surfactometer) and in vivo (using a foetal rabbit bioassay). In both models, lucinactant retained its activity after capillary aerosol generation. Similar findings have been described for bovine surfactant (Jorch 1994). On average $0.08 \%$ to $15 \%$ of total administered aerosolised surfactant could be recovered in animal models (Lewis 1993c; Fok 1998; Bahlmann 2000). Multiple factors are reported to influence aerosol surfactant dose delivery, including patient weight or size; minute ventilation (Cole 2000), aerosol flow and patient peak inspiratory flow; aerosol particle size (as large as possible to avoid potential exhalation yet small enough to bypass the oropharynx) (Mazela 2007); aerosol generator used and type of surfactant (Fok 1998). An ultrasonic nebuliser and colfosceril palmitate (Exosurf) have been shown to have higher deposition than a jet nebuliser and beractant (Survanta) (Fok 1998).

Small human neonatal pilot and case series studies demonstrate conflicting results. Reports include studies showing that nebulised surfactant may reduce the need for endotracheal intubation and is well tolerated (Jorch 1997; Finer 2006), with no adverse effects reported apart from transient oxygen desaturation during dosing, and another report that nebulised surfactant had no beneficial effects (Arroe 1998).

\section{How the intervention might work}


The nebulised surfactant administration technique is designed to emit a continuous dense surfactant microaerosol of diameter less than $2 \mu \mathrm{m}$ ideal for deep lung deposition. The technique is designed to avoid endotracheal intubation yet offer the benefits of surfactant administration. Combining this surfactant administration strategy with antenatal corticosteroid administration and CDP may offer potential synergy to treat RDS, avoiding both endotracheal intubation and PPV, and reducing lung injury that may lead to BPD. In a variety of animal models of induced lung injury, nebulised surfactant improved pulmonary mechanics, lung structure integrity, and reduced lung inflammation, even with minimal deposition in the lungs (Lewis 1991; Lewis 1993a; Wolfson 2008). However, other studies have showed that nebulised surfactant did not improve pulmonary parameters (Fok 1998).

\section{Why it is important to do this review}

Despite significant advances in neonatal intensive care, CLD results in a significant health burden to preterm infants born at less than 32 weeks' gestation who received mechanical ventilation. CLD results in substantial neonatal and infant morbidity and health resource utilisation (Allen 2003). CLD is associated with chronic respiratory difficulties (Kilbride 2003; Doyle 2006), prolonged and recurrent hospitalisation (Chye 1995), neurodevelopmental disability including cerebral palsy, neurosensory and motor disability (Skidmore 1990; Hughes 1999; Majnemer 2000) and poor cognitive outcome (Hughes 1999). CLD has a major impact on the daily life of families that persists beyond the neonatal period (Korhonen 1999). Nebulised surfactant is a physiological and logical technique with the potential benefit of avoiding ventilation, VILI and BPD.

\section{O B J E C T IVES}

To determine the effect of nebulised surfactant administration compared to placebo, no treatment or intratracheal surfactant instillation on morbidity or mortality, or both, in preterm infants at risk for or having RDS.

\section{METHODS}

\section{Criteria for considering studies for this review}

\section{Types of studies}

Published, unpublished and ongoing RCTs; quasi-randomised trials regardless of unit of allocation (individual or cluster) were considered to be eligible for inclusion in this review.

\section{Types of participants}

Preterm infants (less than 37 weeks' gestation) at risk for or having RDS of any severity and at any postnatal age as included in the trials.

We defined prophylactic surfactant therapy as all treatment strategies in which the intent was to treat a preterm infant based on the risk of RDS within the first hour of life. We defined risk of RDS as gestational age of less than 32 weeks or birthweight less than $1250 \mathrm{~g}$.

We defined treatment of established disease ('rescue therapy') as treatment of a preterm infant less than 37 weeks' gestational age requiring respiratory support and having signs and symptoms of RDS.

\section{Types of interventions}

Nebulised surfactant administration at any dose, using any type of surfactant (synthetic, animal derived or protein-containing synthetic), any route of conduit (nasopharyngeal tube, laryngeal airway, nasal prong or face mask), and using any aerosol generator compared with either placebo, no treatment or intratracheal instilled surfactant. We planned to perform separate comparisons for all above comparative groups if trial data were available.

\section{Types of outcome measures}

We planned to study the following primary and secondary outcome measures.

\section{Primary outcomes}

1. CLD defined as need for oxygen or respiratory support at 36 weeks' postmenstrual age (PMA) (Shennan 1988).

2. Mortality prior to hospital discharge.

3. Neurodevelopmental disability assessed at 18 months' postnatal age or later defined as neurological abnormality including cerebral palsy on clinical examination, developmental delay more than two standard deviations below population mean on a standardised test of development, blindness (visual acuity less than 6/60) or deafness (any hearing impairment requiring amplification) at any time after term corrected.

\section{Secondary outcomes}

1. Intratracheal surfactant received post-intervention.

2. Mechanical ventilation.

3. Days on mechanical ventilation.

4. Days on CPAP.

5. Days of high-flow nasal cannula.

6. Days of low-flow nasal cannula.

7. Days of supplemental oxygen administration.

8. Pulmonary interstitial emphysema.

Nebulised surfactant in preterm infants with or at risk of respiratory distress syndrome (Review) 
9. Pneumothorax.

10. Use of high-frequency oscillatory ventilation (HFOV) as a rescue treatment for respiratory distress.

11. Use of jet ventilation as a rescue treatment for respiratory distress.

12. Use of extracorporeal membrane oxygenation (ECMO) as a rescue treatment for respiratory distress.

13. Use of postnatal corticosteroids as rescue treatment for respiratory distress.

14. CLD defined as need for oxygen or respiratory support at 28 days of age.

15. Use of diuretic as a prophylaxis or rescue treatment for CLD.

16. Use of postnatal corticosteroid as a prophylaxis or rescue treatment for CLD.

17. Use of home oxygen.

18. Asthma diagnosed by physician or challenge test.

19. Rehospitalisation for asthma.

20. Rehospitalisation for hyperactive airway disease.

21. Rehospitalisation for pneumonia.

22. Neonatal mortality (mortality at less than 28 days of age).

23. Intraventricular haemorrhage (any and severe - Papile grade 3 or 4) (Papile 1978).

24. Cystic periventricular leukomalacia.

25. Patent ductus arteriosus (PDA) - symptomatic or treated with cyclo-oxygenase inhibitors or surgical ligation.

26. Necrotising enterocolitis (confirmed $=$ Bell stage 2 or greater) (Bell 1978).

27. Retinopathy of prematurity (any and severe $=$ stage 3 or higher) (International Committee 2005).

28. Apnoea treated with methylxanthines or respiratory support.

29. Time to regain birth weight (days).

30. Systemic infection in first 48 hours of life.

31. Postnatal growth failure (weight less than $10^{\text {th }}$ percentile at discharge).

32. Duration of hospitalisation (days).

33. Adverse effect of the intervention including hypoxia and bradycardia during administration.

34. Discontinuation of intervention because of side effects (e.g. bradycardia).

\section{Search methods for identification of studies}

See: Cochrane Neonatal Group methods used in reviews. We used the standard search strategy of the Cochrane Neonatal Review Group (CNRG) as outlined in The Cochrane Library. We considered unpublished studies to be eligible for review. The search of MEDLINE and PREMEDLINE (via OVID interface) included the following MeSH terms and free text words: "infant, premature, preterm, newborn, neonate", "surfactant", "laryngeal”, "mask", "airway". We limited searches to "randomised and quasi- randomised clinical trials" (Appendix 1). We adapted this search strategy to suit other electronic sources like the Cochrane Central Register of Controlled Trials (CENTRAL), EMBASE and CINAHL. We did not apply any language restrictions.

\section{Electronic searches}

We searched the following electronic databases:

1. the Cochrane Central Register of Controlled Trials

(CENTRAL, The Cochrane Library, January 2012);

2. MEDLINE and PREMEDLINE (1950 to January 2012) via OVID interphase;

3. EMBASE (1980 to January 2012) via OVID interphase;

4. CINAHL (1982 to January 2012) via EBSCO interphase;

5. GoogleScholar.

\section{Searching other resources}

We conducted additional searches of the following:

1. Ongoing trials in the following trial registries (searched January 2012): Health);

- ClinicalTrials.gov (U.S. National Institutes of

- Current Controlled Trials;

- Australian New Zealand Clinical Trials Registry;

- International Clinical Trials Registry Platform

(ICTRP).

2. Abstract of conferences from:

- Proceedings of the Pediatric Academic Societies

(American Pediatric Society, Society for Pediatric Research and European Society for Pediatric Research) from 1990 to 2011 from the journal Pediatric Research and Abstracts Online;

- Proceedings of the European Academy of Paediatric Societies (EAPS) (The European Society for Paediatric Research (ESPR), the European Academy of Paediatrics (EAP) and the European Society of Paediatric and Neonatal Intensive Care (ESPNIC)) from 2003 to 2011 from Abstracts Online;

- Proceedings of the Perinatal Society of Australia and New Zealand (PSANZ) from 1996 to 2011 (handsearch).

3. Reference lists: after reading the identified individual studies that examined the effect of laryngeal surfactant installation on the morbidity mortality, or both, in preterm infants at risk of RDS, we screened the reference lists of these papers to identify further relevant studies;

4. Personal communications with expert informants and authors of included studies;

5. Pharmaceutical companies: we contacted the companies that developed different types of surfactant for possible unpublished studies using their product.

\section{Data collection and analysis}


We used the standardised review method of the CNRG for conducting a systematic review (http://neonatal.cochrane.org/en/ index.html). We entered and cross-checked data using Review Manager 5.1 software (RevMan 2011).

\section{Selection of studies}

Both review authors independently reviewed the titles and abstracts of potentially relevant studies against the inclusion and exclusion criteria. The two review authors independently assessed titles and the abstracts of studies identified by the search strategy for eligibility for inclusion in this review. We retrieved full-text versions for closer examination for eligible studies or when inadequate information was provided in the abstract.

\section{Data extraction and management}

Both review authors independently extracted data from the fulltext articles using a specifically designed spreadsheet matrix to manage the information. These forms were used to decide trial inclusion or exclusion, extract data from eligible trials and for requesting additional published information from authors of the original report. We entered and cross-checked data using RevMan 5.1 software (RevMan 2011). We then compared the extracted data for any differences. If noted, we planned to resolve differences by mutual discussion and consensus.

\section{Assessment of risk of bias in included studies}

We used the standardised review methods of the CNRG (http:// neonatal.cochrane.org/en/index.html) to assess the methodological quality of included studies. Review authors independently assessed study quality and risk of bias (see: Characteristics of included studies) using the following criteria documented in the Cochrane Handbook for Systematic Reviews of Interventions (Higgins 2011).

1. Sequence generation: was the allocation sequence adequately generated?

2. Allocation concealment: was allocation adequately concealed?

3. Blinding of participants, personnel and outcome assessors for each main outcome or class of outcomes: was knowledge of the allocated intervention adequately prevented during the study?

4. Incomplete outcome data for each main outcome or class of outcomes: were incomplete outcome data adequately addressed?

5. Selective outcome reporting: are reports of the study free of suggestion of selective outcome reporting?

6. Other sources of bias: was the study apparently free of other problems that could put it at a high risk of bias? We gave particular attention to completeness of follow-up of all randomised infants and to the length of follow-up studies to identify whether any benefits claimed are robust.

When necessary, we requested additional information and clarification of published data from the authors of individual trials. We assessed each trial for risk of bias based on the criteria listed above and marked as:

- low risk of bias;

- unclear risk of bias;

- high risk of bias.

We resolved discrepancies by mutual discussion and consensus. We planned to provide levels of agreement among review authors and details of resolution of any differences.

\section{Measures of treatment effect}

We analysed treatment effects in the individual trials using RevMan 5.1 (RevMan 2011).

\section{Dichotomous data}

We reported dichotomous data using risk ratio (RR) and risk difference (RD), each with $95 \%$ confidence interval (CI). If there was a statistically significant reduction in $\mathrm{RD}$ we then calculated the number needed to treat for a beneficial outcome (NNTB) or number needed to treat for a harmful outcome (NNTH) and associated $95 \%$ CI.

\section{Continuous data}

We reported continuous data using mean difference (MD) with $95 \%$ CI.

\section{Unit of analysis issues}

The unit of randomisation was the intended unit of analysis and we expected this to be individual infants. Cluster RCTs were planned to be included.

\section{Cluster randomised trials}

We planned to include cluster-randomised trials in the analyses, along with individually randomised trials, using methods described in the Cochrane Handbook for Systematic Reviews of Interventions (Higgins 2011) using an estimate of the intra-cluster correlation coefficient (ICC) derived from the trial (if possible), or from another source. If ICCs from other sources were used, we planned to report this and conduct sensitivity analyses to investigate the effect of variation in the ICC. If we had identifies both cluster randomised trials and individually randomised trials, we planned to synthesise the relevant information. We considered it reasonable to combine the results from both if there was little heterogeneity between study designs, and the interaction between the effect of intervention and the choice of randomisation unit was considered to be unlikely. 


\section{Dealing with missing data}

We planned to obtain missing data from the study authors when possible. If this was not possible, then we planned to conduct analyses on available data (i.e. ignoring the missing data). In addition, we planned to conduct another analysis by using an imputation method (both best- and worst-case scenarios) and last observation carried forward to the final assessment (LOCF) method for dichotomous and continuous outcome data, respectively.

For dichotomous outcomes we planned to conduct both best- and worst-case scenarios and intention-to-treat (ITT) analysis with imputation. We planned to compare results obtained from two analysis options to have a better understanding of the robustness of results relative to the different analytic approaches. We planned to consider an imputation approach of best-case scenarios (i.e. all missing participants in the intervention group did not experience poor outcomes (e.g. death, BPD) and all missing participants in the control group experienced poor outcomes) and worst-case scenarios (i.e. all missing participants in the intervention group experienced the event and all missing participants in the control condition did not). We planned to conduct sensitivity analysis to compare results based on different imputation assumptions (i.e. best- versus worst-case scenarios).

We planned to analyse missing continuous data on an end point basis, including only participants with a final assessment, or using LOCF if the trial authors report any LOCF data.

\section{Assessment of heterogeneity}

We used RevMan 5.1 (RevMan 2011) to assess the heterogeneity of treatment effects between trials. We used the two formal statistics described below.

1. The Chi ${ }^{2}$ test, to assess whether observed variability in effect sizes between studies was greater than would be expected by chance. Since this test has low power when the number of studies included in the meta-analysis is small, we planned to set the probability at the $10 \%$ level of significance.

2. The $\mathrm{I}^{2}$ statistic to ensure that pooling of data was valid. We planned to grade the degree of heterogeneity as: $0 \%$ to $30 \%$ : might not be important; $31 \%$ to 50\%: moderate heterogeneity; $51 \%$ to $75 \%$ : substantial heterogeneity; $76 \%$ to $100 \%$ : considerable heterogeneity.

Where there was evidence of apparent or statistical heterogeneity, we planned to assess the source of the heterogeneity using sensitivity and subgroup analysis looking for evidence of bias or methodological differences between trials.

\section{Assessment of reporting biases}

We planned to investigate reporting and publication bias by examining the degree of asymmetry of a funnel plot. RevMan 5.1 (RevMan 2011) has the capability to produce this graph, which plots the effect size estimated from each individual study against some measure of study sample size. A symmetrical appearance of the funnel plot will indicate absence of publication bias. Otherwise, existence of bias is related to the degree of asymmetry.

\section{Data synthesis}

We planned to perform statistical analyses according to the recommendations of CNRG (http://neonatal.cochrane.org/en/ index.html). We planned to analyse all infants randomised on an ITT basis. We planned to analyse treatment effects in the individual trials. We planned to use a fixed-effect model in the first instance to combine the data. For any meta-analyses, for categorical outcomes we planned to calculate typical estimates of RR and $\mathrm{RD}$, each with $95 \% \mathrm{CI}$; for continuous outcomes we planned to calculate the MD if outcomes were measured in the same way between trials, and standardised mean difference (SMD) to combine trials that measured the same outcome, but use different scales. When we judged meta-analysis to be inappropriate, we planned to analyse and interpret individual trials separately.

\section{Subgroup analysis and investigation of heterogeneity}

Providing sufficient data were available, we planned to explore potential sources of clinical heterogeneity through the following a priori subgroup analyses:

1. timing of nebulised surfactant administration: prophylactic, early rescue (within the first two hours of life), late rescue (within the first week of life), or very late rescue (after the first week of life);

2. type of surfactant aerosol generator used (jet, ultrasonic or vibrating membrane nebuliser);

3. aerosol particle diameter regardless of aerosol generator and type of surfactant used ( $2 \mu \mathrm{m}$ or less, greater than $2 \mu \mathrm{m}$ in diameter);

4. type of surfactant used (specialised surfactant made for inhalation, other non-specialised surfactant) regardless of being synthetic or natural;

5. route of administration (nasopharyngeal tube, laryngeal airway, nasal prong or face mask);

6. type of surfactant used (synthetic, animal derived or protein-containing synthetic);

7. gestational age at delivery (less than 28,28 to 31,32 to 34 and 35 or greater completed weeks' gestation).

\section{Sensitivity analysis}

Where sufficient data were available, we planned to explore methodological heterogeneity through the use of sensitivity analyses, which will serve to test the degree of robustness of the results obtained by the meta-analysis. We planned to perform sensitivity analyses through excluding trials of lower quality, based on a lack of any of the following: allocation concealment, adequate 
randomisation, blinding of treatment, less than $10 \%$ loss to follow-up. Sensitivity analysis for effect of losses would include an analysis using LOCF and imputation analysis (as above).

\section{RE S U L T S}

\section{Description of studies}

See: Characteristics of included studies; Characteristics of excluded studies.

\section{Results of the search}

See: Characteristics of included studies; Characteristics of excluded studies.

A total of five reports were considered for this review. Four were eliminated because they did not involve random allocation, a control group, or both (Jorch 1997; Arroe 1998; Finer 2010) or did involve infant-simulator only (Pearson 2005). One study (Berggren 2000) was included in the present review. Details of this study are provided in the Characteristics of included studies table. No ongoing trials were identified.

\section{Included studies}

\section{Types of participants}

Berggren 2000 enrolled 34 preterm infants, with 32 infants reported who met inclusion criteria including clinically and radiologically diagnosed RDS, corrected gestational age $<36$ weeks, age two to 36 hours, arterio/alveolar oxygen tension ratio $\left(\mathrm{a} / \mathrm{A} \mathrm{pO}_{2}\right)$ 0.15 to 0.22 , fraction inspired oxygen $\left(\mathrm{FiO}_{2}\right)$ needed to maintain arterial oxygen saturation $\left(\mathrm{SaO}_{2}\right) 85 \%$ to $95 \%$; transcutaneous partial pressure oxygen $\left(\mathrm{tcpO}_{2}\right) 6$ to $8 \mathrm{kPa}$ tcpO 6 to $8 \mathrm{kPa}$, partial pressure oxygen $\left(\mathrm{PaO}_{2}\right) 7.5$ to $9 \mathrm{kPa}>0.4$, and no evidence of lung or cardiovascular malformation. Two infants were later excluded because they did not fulfil the inclusion criteria.

\section{Types of interventions}

Berggren 2000 compared $480 \mathrm{mg}$ of nebulised surfactant (Curosurf) generated via jet aerosol generator (Aiolos ${ }^{\circledR}$, Karlstad, Sweden) and given via nCPAP equipment versus no treatment. There was no standard 'failure criteria', but in most cases a/ $\mathrm{A} \mathrm{pO}_{2}<0.15$ was considered as an indication for intubation and ventilation.

\section{Types of outcomes measures}

Berggren 2000 reported the following:

- a/A $\mathrm{pO}_{2}$ at 0, 2, 4, 6 and 12 hours post-randomisation;

- air leak;

- requirement of mechanical ventilation;

- duration of mechanical ventilation;

- duration of CPAP;

- duration of oxygen supplement;

- PDA;

- pathological cerebral ultrasound at one week;

- CLD.

Neurodevelopmental disability and some of the pre-specified secondary outcome measures of the review were not reported by Berggren 2000.

\section{Excluded studies}

No other randomised, cluster-randomised or quasi-RCTs were identified for exclusion from the review. Four observational nonrandomised and non-controlled studies were identified and excluded from this review (Jorch 1997; Arroe 1998; Pearson 2005; Finer 2010).

\section{Risk of bias in included studies}

The single included study (Berggren 2000) was at moderate risk of bias. Although the study reported an ITT analysis, the study had unclear sequence generation and methods for maintaining allocation concealment, lacked blinding and standardised failure criteria, and had analyses of multiple respiratory end points. Ratings of methodological quality are given in the Characteristics of included studies table.

\section{Allocation}

Berggren 2000 randomised infants using a centralised scheme. Method of sequence generation was not reported. Allocation was concealed by using sealed envelopes.

\section{Blinding}

Berggren 2000 did not mask investigators, outcome assessors or families to study group.

\section{Incomplete outcome data}

Berggren 2000 reported 2/34 (6\%) infants excluded (one in each group) post allocation as not meeting enrolment criteria. 


\section{Selective reporting}

Primary outcomes were not specific - described as 'safety and need for mechanical ventilation' (Berggren 2000).

\section{Other potential sources of bias}

Indication for intubation and ventilation (failure of intervention) was not standardised, but in most cases a/ $\mathrm{A} \mathrm{pO}_{2}<0.15$ was considered as an indication for intubation and ventilation. $\mathrm{pH}$ was lower in the treatment group compared to controls at randomisation (7.29 versus 7.32; $\mathrm{P}<0.019)$.

\section{Effects of interventions}

\section{Prophylactic treatment of preterm infants with nebulised surfactant versus no treatment}

No studies were found that enrolled infants at risk of RDS irrespective of the need for respiratory support or diagnosis of RDS.

\section{Treatment of RDS with nebulised surfactant versus no treatment (Comparison I)}

One study compared treatment of RDS with nebulised surfactant versus no treatment (Berggren 2000).

\section{Primary outcome measures}

\section{Chronic lung disease at 36 weeks' postmenstrual age}

Berggren 2000 reported no significant difference in CLD (32 infants; RR 5.00; 95\% CI 0.26 to 96.59) (Analysis 1.1). Test for heterogeneity not applicable.

Mortality and neurodevelopmental outcome were not reported.

\section{Secondary outcome measures}

Berggren 2000 reported no significant difference in mechanical ventilation (RR 1.20; 95\% CI 0.46 to 3.15) (Analysis 1.2), air leak (RR 1.00; 95\% CI 0.30 to 3.32) (Analysis 1.3), PDA (RR 1.50; $95 \%$ CI 0.29 to 7.81 ) (Analysis 1.4 ) or pathological cerebral ultrasound at one week (RR 0.29 ; 95\% CI 0.01 to 6.50 ) (Analysis 1.5). Berggren 2000 reported no significant difference in median days of IPPV (intervention six days versus control five days), CPAP (intervention seven days versus control six days) and oxygen (intervention 15 days versus control seven days). Test for heterogeneity not applicable.

Other secondary outcome measures were not reported.

\section{Subgroup analyses}

The following subgroup analyses were pre-specified. As only one study reported data, the outcomes are as reported above.

1. Timing of nebulised surfactant administration: prophylactic, early rescue (within the first two hours of life), late rescue (within the first week of life), or very late rescue (after the first week of life): Berggren 2000 reported late rescue treatment (mean age at treatment 19 hours).

2. Type of surfactant aerosol generator used (jet, ultrasonic or vibrating membrane nebuliser): Berggren 2000 reported use of jet aerosol generator (Aiolos ${ }^{\circledR}$, Karlstad, Sweden).

3. Aerosol particle diameter regardless of aerosol generator and type of surfactant used ( $2 \mu \mathrm{m}$ or less, greater than $2 \mu \mathrm{m}$ in diameter): Berggren 2000 reported $99 \%$ of the particles in the aerosol had a diameter $<2 \mu \mathrm{m}$.

4. Type of surfactant used (specialised surfactant made for inhalation, other non-specialised surfactant) regardless of being synthetic or natural: Berggren 2000 reported use of nonspecialised surfactant (Curosurf1, Chiesi Farmaceutici, Parma, Italy).

5. Type of surfactant used (synthetic, animal derived or protein-containing synthetic): Berggren 2000 reported use of animal derived surfactant (Curosurf1, Chiesi Farmaceutici, Parma, Italy).

6. Route of administration (nasopharyngeal tube, laryngeal airway, nasal prong or face mask): Berggren 2000 reported administration via nasal prongs using nasal CPAP circuit (Infant Flow System1, Dansjo Medical AB, Bromma, Sweden).

7. Gestational age at delivery (less than 28,28 to 31,32 to 34 and 35 or greater completed weeks' gestation): Berggren 2000 enrolled infants with median gestational age 31 weeks (range 28 to 34 weeks) and median birth weight 1603 to $1620 \mathrm{~g}$ (range 755 to $2855 \mathrm{~g}$ ).

\section{Sensitivity analysis}

We planned to perform a sensitivity analysis based on the following: inadequate randomisation, allocation concealment or blinding of treatment, or greater than $10 \%$ loss to follow-up. Berggren 2000 reported unclear randomisation and allocation concealment, and $6 \%$ losses post randomisation. Berggren 2000 reported no masking of investigators, outcome assessors or families to study group.

\section{DISCUSSION}

\section{Summary of main results}

Only one small study was identified and found to be eligible for inclusion. This study enrolled preterm infants with RDS on nCPAP 
and reported no significant differences between nebulised surfactant and control group in CLD, a/A $\mathrm{pO}_{2} 1$ to 12 hours after randomisation, number of infants needing mechanical ventilation, time on ventilator or CPAP, or duration of oxygen supplement. No side effects of the nebulised surfactant therapy or aerosol inhalation were noted.

\section{Overall completeness and applicability of evidence}

The single small study included in the review reported outcomes for 32 preterm infants with RDS on nCPAP and used nebulised surfactant as treatment of established RDS. The data are largely applicable to late treatment of established RDS in relatively mature preterm infants. However, the study was underpowered to detect important clinical benefits and harms of nebulised surfactant for treatment of RDS. Furthermore, the study is of moderate risk of bias.

No study was found that examined the effect of nebulised surfactant administration for prevention of RDS (e.g. at resuscitation) or early treatment of RDS in keeping with the known benefits of prophylactic (Rojas-Reyes 2012) and early surfactant treatment (Stevens 2007) in very preterm infants.

\section{Quality of the evidence}

The single included study (Berggren 2000) was of moderate risk of bias. The study was unblinded, had unclear sequence generation, lacked standard definition for failure criteria (intubation and ventilation) and had analysis of multiple respiratory end points.

\section{Potential biases in the review process}

An extensive search for published and unpublished literature was performed including searches of trial registries for ongoing studies. Two review authors independently assessed eligibility, study quality and extracted data. Agreement was reached through consensus.

\section{Agreements and disagreements with other studies or reviews}

Berggren 2000 and Arroe 1998; demonstrated no beneficial effects of nebulised surfactant, either during the period of nebulisation or after the nebulisation. The discrepancy between these negative results and other pilot observations (Jorch 1997; Pearson 2005; Finer 2010) might be attributed to multiple factors:

- excessive loss of aerosolised surfactant in the nCPAP device: Jorch 1997 reported successful treatment of RDS by aerosolised surfactant using a jet nebuliser and delivery of the aerosol via a nasopharyngeal tube. This is may raise the issue of excessive loss when using nCPAP;

- size of the particles in the generated aerosol: however a diameter $<2 \mu \mathrm{m}$ as used by Berggren 2000 should be ideal for deposition in peripheral airspaces;

- the effectiveness of delivery of aerosolised surfactant: the effectiveness of delivery of aerosolised surfactant depends on the type of aerosol generator (jet, ultrasonic or vibrating membrane nebuliser). Arzhavitina 2010 hypothesise that a vibrating membrane nebuliser is the best device for substances with surface activity such as surfactant, as the residual volume in the device is minimal and the substance output maximal. These results still need confirmation by in vivo studies;

- timing of nebulised surfactant administration: for endotracheal administration prophylactic (Soll 1998) and early surfactant treatment (Soll 1999) have been demonstrated to be more beneficial.

A non-systematic review of literature by Mazela 2007 concluded that nebulised surfactant is a potentially beneficial strategy for non-invasive surfactant delivery and further studies are needed.

\section{AUTHORS' CONCLUSIONS}

\section{Implications for practice}

A single underpowered study of jet-nebulised animal-derived surfactant in preterm infants did not detect any benefits or harms in preterm infants with established RDS on CPAP. There are insufficient data to support or refute its use in clinical practice. Nebulised surfactant administration should be limited to clinical trials.

\section{Implications for research}

Adequately powered trials with appropriately designed delivery systems are required to determine the effect of nebulised surfactant administration for prevention or treatment of RDS in preterm infants. Studies should measure short- and long-term outcomes prespecified in this review. Given the evidence for prophylactic and early surfactant administration, trials should enrol infants early in the course of respiratory illness.

Currently there are no ongoing registered trials for nebulised surfactant with ClinicalTrials.gov (searched 27 January 2012).

\section{ACK NOW LEDGEMENTS}

As part of the pre-publication editorial process, this protocol has been commented on by three peers (an editor and two referees who are external to the editorial team) and the Group's Statistical Adviser. 


\section{R E F E R E N C E S}

\section{References to studies included in this review}

Berggren 2000 \{published data only\}

Berggren E, Liljedahl M, Winbladh B, Andreasson B, Curstedt T, Robertson B, et al.Pilot study of nebulized surfactant therapy for neonatal respiratory distress syndrome. Acta Paediatrica 2000;89(4):460-4.

\section{References to studies excluded from this review}

Arroe 1998 \{published data only\}

Arroe M, Pedersen-Bjergaard L, Albertsen P, Bode S, Greisen G, Jonsbo F. Inhalation of aerosolized surfactant Exosurf $^{\circledR}$ to neonates treated with nasal continuous positive airway pressure. Prenatal and Neonatal Medicine 1998;3(3): $346-52$.

Finer 2010 \{published data only\}

Finer NN, Merritt TA, Bernstein G, Job L, Mazela J, Liu G. A multicenter pilot study of Aerosurf ${ }^{T M}$ delivered via nasal continuous positive airway pressure (nCPAP) to prevent respiratory distress syndrome in preterm neonates. Proceeding of the 2006 Pediatric Academic Societies Annual Meeting. San Francisco, CA, USA. Pediatric Research. 2006; Vol. 59:4840.138.

Finer NN, Merritt TA, Bernstein G, Job L, Mazela J, Segal R. An open label, pilot study of Aerosurf ${ }^{\circledR}$ combined with $\mathrm{nCPAP}$ to prevent RDS in preterm neonates. Journal of Aerosol Medicine and Pulmonary Drug Delivery 2010;23(5): 303-9.

Jorch 1997 \{published data only\}

Jorch G, Hartl H, Roth B, Kribs A, Gortner L, Schaible $\mathrm{T}$, et al.Surfactant aerosol treatment of respiratory distress syndrome in spontaneously breathing premature infants. Pediatric Pulmonology 1997;24(3):222-4.

Jorch G, Weller E, Murlat A, Hentschel R. Feasibility study on nebulization of bovine surfactant (SF-RI 1) by pharyngeal continuous positive airway pressure (CPAP). Biology of the Neonate 1994;66:166.

Pearson 2005 \{published data only\}

Pearson R, Pippins M, Niven R, Johnson ME. Treatment of RDS using aerosolized KL4 lung surfactant in combination with nCPAP. Proceeding of the 2005 European Society for Pediatric Research Annual Meeting. Siena, Italy. Pediatric Research. 2005; Vol. 58(2):386.

\section{Additional references}

\section{Allen 2003}

Allen J, Zwerdling R, Gaultier C, Geggel R, Greenough A, Kleinman R, et al.Statement on the care of the child with chronic lung disease of infancy and childhood. American Journal of Respiratory and Critical Care Medicine 2003;168 (3):356-96.

\section{Aly 2001}

Aly HZ. Nasal prongs continuous positive airway pressure: a simple yet powerful tool. Pediatrics 2001;108(3):759-61.
Aly 2008

Aly H, Badawy M, El-Kholy A, Nabil R, Mohamed A. Randomized, controlled trial on tracheal colonization of ventilated infants: can gravity prevent ventilator-associated pneumonia?. Pediatrics 2008;122(4):770-4.

Arzhavitina 2010

Arzhavitina A, Steckel H. Surface active drugs significantly alter the drug output rate from medical nebulizers.

International Journal of Pharmaceutics 2010;384:128-136.

Bahlmann 2000

Bahlmann H, Sun B, Nilsson G, Curstedt T, Robertson B. Aerosolized surfactant in lung-lavaged adult rats: factors influencing the therapeutic response. Acta Anaesthesiologica Scandinavica 2000;44(5):612-22.

Bell 1978

Bell MJ, Ternberg JL, Feigin RD, Keating JP, Marshall $\mathrm{R}$, Barton L, et al.Neonatal necrotizing enterocolitis. Therapeutic decisions based upon clinical staging. Annals of Surgery 1978;187(1):1-7.

Björklund 1997

Björklund LJ, Ingimarsson J, Curstedt T, John J, Robertson $\mathrm{B}$, Werner $\mathrm{O}$, et al.Manual ventilation with a few large breaths at birth compromises the therapeutic effect of subsequent surfactant replacement in immature lambs. Pediatric Research 1997;42(3):348-55.

Bohlin 2007

Bohlin K, Gudmundsdottir T, Katz-Salamon M, Jonsson B, Blennow M. Implementation of surfactant treatment during continuous positive airway pressure. Journal of Perinatology 2007;27(7):422-7.

\section{Chye 1995}

Chye JK, Gray PH. Rehospitalization and growth of infants with bronchopulmonary dysplasia: a matched control study. Journal of Paediatrics and Child Health 1995;31(2):105-11.

\section{Clark 2000}

Clark RH, Slutsky AS, Gerstmann DR. Lung protective strategies of ventilation in the neonate: what are they?. Pediatrics 2000;105(1 Pt 1):112-4.

\section{Coalson 1999}

Coalson JJ, Winter VT, Siler-Khodr T. Neonatal chronic lung disease in extremely immature baboons. American Journal of Respiratory and Critical Care Medicine 1999;160 (4):1333-6.

\section{Cole 2000}

Cole C. Special problems in aerosol delivery: neonatal and pediatric considerations. Respiratory Care 2000;45(6): 646-51.

Dargaville 2011 Dargaville PA, Aiyappan A, Cornelius A, Williams C, de Paoli AG. Preliminary evaluation of a new technique of minimally invasive surfactant therapy. Archives of Disease in Childhood Fetal and Neonatal Edition 2011;96:F243-8. 


\section{Davis 2008}

Davis PG, Lemyre B, De Paoli AG. Nasal intermittent positive pressure ventilation (NIPPV) versus nasal continuous positive airway pressure (NCPAP) for preterm neonates after extubation. Cochrane Database of Systematic Reviews 2008, Issue 2. [DOI: 10.1002/ 14651858.CD003212]

\section{DeKlerk 2001}

DeKlerk AM, DeKlerk RK. Use of continuous positive airway pressure in preterm infants: comments and experience from New Zealand. Pediatrics 2001;108(3): $761-2$.

\section{Doyle 2006}

Doyle LW, Victorian Infant Collaborative Study Group. Respiratory function at age 8-9 years in extremely low birthweight/very preterm children born in Victoria in 19911992. Pediatric Pulmonology 2006;41(6):570-6.

\section{Dunn 2011}

Dunn MS, Kaempf J, de Klerk A, de Klerk R, Reilly M, Howard D, et al.Randomized trial comparing 3 approaches to the initial respiratory management of preterm neonates. Pediatrics 2011;128:e1069-76.

Finer 2006

Finer NN, Merritt TA, Bernstein G, Job L, Mazela J, Liu G. A multicenter, pilot study of Aerosurf delivered via nasal CPAP to prevent RDS in pre-term neonates. Proceeding of the 2006 Pediatric Academic Societies Annual Meeting. San Francisco, CA, USA, 2006:59:4840.138.

\section{Flecknoe 2008}

Flecknoe SJ, Crossley KJ, Lane MA, Allison BJ, Morley CJ, Hooper SB. The effects of mechanical ventilation on airway epithelium in near term and very preterm sheep [Abstract]. Journal of Paediatrics and Child Health 2008;44(1):A42.

\section{Fok 1998}

Fok TF, al Essa M, Dolovich M, Rasid F, Kirpalani H. Nebulisation of surfactant in an animal model of neonatal respiratory distress. Archives of Disease in Childhood Fetal Neonatal Edition 1998;78(1):F3-9.

\section{Ghanta 2007}

Ghanta S, Abdel-Latif ME, Lui K, Ravindranathan H, Awad A, Oei J. Propofol compared with the morphine, atropine, and suxamethonium regimen as induction agents for neonatal endotracheal intubation: a randomized, controlled trial. Pediatrics 2007;119(6):e1248-55.

\section{Grossmann 1986}

Grossmann G, Nilsson R, Robertson B. Scanning electron microscopy of epithelial lesions induced by artificial ventilation of the immature neonatal lung; the prophylactic effect of surfactant replacement. European Journal of Pediatrics 1986;145(5):361-7.

\section{Hellstrom-Westas 1992}

Hellstrom-Westas L, Bell AH, Skov L, Greisen G, Svenningsen NW. Cerebroelectrical depression following surfactant treatment in preterm neonates. Pediatrics 1992; 89(4 Pt 1):643-7.

\section{Higgins 2011}

Higgins JPT, Green S (editors). Cochrane Handbook for Systematic Reviews of Interventions Version 5.1.0 [updated March 2011]. The Cochrane Collaboration, 2011. Available from www.cochrane-handbook.org.

Ho 2002a

Ho JJ, Subramaniam P, Henderson-Smart DJ. Continuous distending pressure for respiratory distress syndrome in preterm infants. Cochrane Database of Systematic Reviews 2002, Issue 1. [DOI: 10.1002/14651858.CD002271]

Ho 2002b

Ho JJ, Henderson-Smart DJ, Davis PG. Early versus delayed initiation of continuous distending pressure for respiratory distress syndrome in preterm infants. Cochrane Database of Systematic Reviews 2002, Issue 2. [DOI: 10.1002/14651858.CD002975]

\section{Hughes 1999}

Hughes CA, O’Gorman LA, Shyr Y, Schork MA, Bozynski ME, McCormick MC. Cognitive performance at school age of very low birth weight infants with bronchopulmonary dysplasia. Journal of Developmental and Behavioral Pediatrics 1999;20(1):1-8.

International Committee 2005

International Committee for the Classification of Retinopathy of Prematurity. The international classification of retinopathy of prematurity revisited. Archives of Ophthalmology 2005;123:991-9.

\section{Johnson 2006}

Johnson M, Mazela J, Pearson R, Rairkar M. KL4-surfactant (Aerosurf) retains surface activity after aerosolization. 8th European Conference on Pediatric and Neonatal Ventilation. Montroux, Switzerland, 2006.

\section{Johnson 2007}

Johnson ME, Rodriguez L, Pearson R, Rairkar M. KL4-surfactant (Aerosurf) retains surface activity after aerosolization. Proceeding of the 2007 Pediatric Academic Societies' Annual Meeting. Toronto, Canada, 2007:751712.

\section{Jorch 1994}

Jorch G, Weller E, Murlat A, Hentschel R. Feasibility study on nebulization of bovine surfactant by pharyngeal continuous positive airway pressure. Biology of the Neonate 1994;66:166.

\section{Kamper 1999}

Kamper J. Early nasal continuous positive airway pressure and minimal handling in the treatment of very-lowbirthweight infants. Biology of the Neonate 1999;76(Suppl 1):22-8.

\section{Kattwinkel 2004}

Kattwinkel J, Robinson M, Bloom B, Delmore P, Ferguson JE. Technique for intrapartum administration of surfactant without requirement for an endotracheal tube. Journal of Perinatology 2004;24(6):360-5.

Kilbride 2003

Kilbride HW, Gelatt MC, Sabath RJ. Pulmonary function and exercise capacity for ELBW survivors in preadolescence: 
effect of neonatal chronic lung disease. Journal of Pediatrics 2003;143(4):488-93.

Korhonen 1999

Korhonen P, Koivisto AM, Ikonen S, Laippala P, Tammela O. Very low birthweight, bronchopulmonary dysplasia and health in early childhood. Acta Paediatrica 1999;88(12): 1385-91.

\section{Kribs 2007}

Kribs A, Pillekamp F, Hú sneler C, Vierzig A, Roth B. Early administration of surfactant in spontaneous breathing with nCPAP: feasibility and outcome in extremely premature infants (postmenstrual age $</=27$ weeks). Paediatric Anaesthesia 2007;17(4):364-9.

Kribs 2010

Kribs A, Härtel C, Kattner E, Vochem M, Küster H, Möller $\mathrm{J}$, et al.Surfactant without intubation in preterm infants with respiratory distress: first multi-center data. Klinische Padiatrie 2010;222(1):13-7.

\section{Kugelman 2007}

Kugelman A, Feferkorn I, Riskin A, Chistyakov I, Kaufman B, Bader D. Nasal intermittent mandatory ventilation versus nasal continuous positive airway pressure for respiratory distress syndrome: a randomized, controlled, prospective study. The Journal of Pediatrics 2007;150(5):521-6.

\section{Lemyre 2002}

Lemyre B, Davis PG, De Paoli AG. Nasal intermittent positive pressure ventilation (NIPPV) versus nasal continuous positive airway pressure (NCPAP) for apnea of prematurity. Cochrane Database of Systematic Reviews 2002, Issue 1. [DOI: 10.1002/14651858.CD002272]

Lewis 1991

Lewis JF, Ikegami M, Jobe AH, Tabor B. Aerosolized surfactant treatment of preterm lambs. Journal of Applied Physiology 1991;70(2):869-76.

\section{Lewis 1993a}

Lewis JF, Tabor B, Ikegami M, Jobe AH, Joseph M, Absolom D. Lung function and surfactant distribution in saline-lavaged sheep given instilled vs. nebulized surfactant. Journal of Applied Physiology 1993;74(3):1256-64.

\section{Lewis 1993b}

Lewis JF, Ikegami M, Jobe AH, Absolom D. Physiologic responses and distribution of aerosolized surfactant (Survanta) in a nonuniform pattern of lung injury. American Review of Respiratory Disease 1993;147(6 Pt 1):1364-70.

Lewis 1993c

Lewis J, McCaig L. Aerosolized versus instilled exogenous surfactant in a nonuniform pattern of lung injury. American Review of Respiratory Disease 1993;148(5):1187-93.

\section{Majnemer 2000}

Majnemer A, Riley P, Shevell M, Birnbaum R, Greenstone $\mathrm{H}$, Coates AL. Severe bronchopulmonary dysplasia increases risk for later neurological and motor sequelae in preterm survivors. Developmental Medicine and Child Neurology 2000;42(1):53-60.

\section{Marshall 1984}

Marshall T, Deeder R, Pai S, Berkowitz GP, Austin TL. Physiologic changes associated with endotracheal intubation in preterm infants. Critical Care Medicine 1984;12(6): 501-3.

\section{Mazela 2007}

Mazela J, Merritt TA, Finer NN. Aerosolized surfactants. Current Opinion in Pediatrics 2007;19(2):155-62.

\section{Morley 2008}

Morley CJ, Davis PG, Doyle LW, Brion LP, Hascoet JM, Carlin JB, COIN Trial Investigators. Nasal CPAP or intubation at birth for very preterm infants. New England Journal of Medicine 2008;358(7):700-8.

\section{O'Reilly 2008}

O'Reilly M, Hooper SB, Allison BJ, Snibson K, Harding R, Sozo F. Airway remodeling and pulmonary inflammation in a model of ventilator-induced injury of the very preterm lung [Abstract]. Journal of Paediatrics and Child Health 2008;44(1):A63.

Papile 1978

Papile L-A, Burstein J, Burstein R, Koffler H. Incidence and evolution of subependymal and intraventricular hemorrhages; a study of infants with birth weights less than 1500 grams. Journal of Pediatrics 1978;92:529-34.

\section{Petrikovsky 1995}

Petrikovsky BM, Lysikiewicz A, Markin LB, Slomko Z. In utero surfactant administration to preterm human fetuses using endoscopy. Fetal Diagnosis and Therapy 1995;10(2): $127-30$.

\section{Pfister 2007}

Pfister RH, Soll RF, Wiswell T. Protein containing synthetic surfactant versus animal derived surfactant extract for the prevention and treatment of respiratory distress syndrome. Cochrane Database of Systematic Reviews 2007, Issue 4. [DOI: 10.1002/14651858.CD006069.pub3]

\section{Pfister 2009}

Pfister RH, Soll R, Wiswell TE. Protein-containing synthetic surfactant versus protein-free synthetic surfactant for the prevention and treatment of respiratory distress syndrome. Cochrane Database of Systematic Reviews 2009, Issue 4. [DOI: 10.1002/14651858.CD006180.pub2]

\section{Reininger 2005}

Reininger A, Khalak R, Kendig JW, Ryan RM, Stevens TP, Reubens $\mathrm{L}$, et al.Surfactant administration by transient intubation in infants 29 to 35 weeks' gestation with respiratory distress syndrome decreases the likelihood of later mechanical ventilation: a randomized controlled trial. Journal of Perinatology 2005;25(11):703-8.

\section{RevMan 2011}

The Nordic Cochrane Centre, The Cochrane Collaboration. Review Manager (RevMan). 5.1. Copenhagen: The Nordic Cochrane Centre, The Cochrane Collaboration, 2011.

\section{Rojas-Reyes 2012}

Rojas-Reyes MX, Morley CJ, Soll R. Prophylactic versus selective use of surfactant in preventing morbidity and 
mortality in preterm infants. Cochrane Database of Systematic Reviews 2012, Issue 3. [DOI: 10.1002/ 14651858.CD000510.pub2]

\section{Sarkar 2006}

Sarkar S, Schumacher RE, Baumgart S, Donn SM. Are newborns receiving premedication before elective intubation?. Journal of Perinatology 2006;26(5):286-9.

Seger 2009

Seger N, Soll R. Animal derived surfactant extract for treatment of respiratory distress syndrome. Cochrane Database of Systematic Reviews 2009, Issue 2. [DOI: 10.1002/14651858.CD007836]

\section{Shennan 1988}

Shennan AT, Dunn MS, Ohlsson A, Lennox K, Hoskins EM. Abnormal pulmonary outcomes in premature infants: prediction from oxygen requirement in the neonatal period. Pediatrics 1988;82(42):527-32.

Skidmore 1990

Skidmore MD, Rivers A, Hack M. Increased risk of cerebral palsy among very low-birthweight infants with chronic lung disease. Developmental Medicine and Child Neurology 1990; 32(4):325-32.

\section{Soll 1997}

Soll RF. Prophylactic animal derived surfactant extract for preventing morbidity and mortality in preterm infants. Cochrane Database of Systematic Reviews 1997, Issue 4. [DOI: 10.1002/14651858.CD000511]

\section{Soll 2000}

Soll RF. Synthetic surfactant for respiratory distress syndrome in preterm infants. Cochrane Database of Systematic Reviews 2000, Issue 2. [DOI: 10.1002/ 14651858.CD001149]

\section{Soll 2001}

Soll RF, Blanco F. Natural surfactant extract versus synthetic surfactant for neonatal respiratory distress syndrome. Cochrane Database of Systematic Reviews 2001, Issue 2. [DOI: 10.1002/14651858.CD000144]

\section{Soll 2009}

Soll R, Özek E. Multiple versus single doses of exogenous surfactant for the prevention or treatment of neonatal respiratory distress syndrome. Cochrane Database of Systematic Reviews 2009, Issue 4. [DOI: 10.1002/ 14651858.CD000141.pub2]

\section{Soll 2010}

Soll R, Ozek E. Prophylactic protein free synthetic surfactant for preventing morbidity and mortality in preterm infants. Cochrane Database of Systematic Reviews 2010, Issue 1. [DOI: 10.1002/14651858.CD001079.pub2]

\section{Stevens 2007}

Stevens TP, Blennow M, Myers EW, Soll R. Early surfactant administration with brief ventilation vs. selective surfactant and continued mechanical ventilation for preterm infants with or at risk for respiratory distress syndrome. Cochrane Database of Systematic Reviews 2007, Issue 2. [DOI: 10.1002/14651858.CD003063.pub3]

\section{SUPPORT Study Group 2010}

SUPPORT Study Group of the Eunice Kennedy Shriver NICHD Neonatal Research Network. Early CPAP versus surfactant in extremely preterm infants. New England Journal of Medicine 2010;362(21):1970-9.

\section{Tooley 1987}

Tooley WH, Clements JA, Muramatsu K, Brown CL, Schlueter MA. Lung function in prematurely delivered rabbits treated with a synthetic surfactant. American Review of Respiratory Disease 1987;136(3):651-6.

\section{Trevisanuto 2005}

Trevisanuto D, Grazzina N, Ferrarese P, Micaglio M, Verghese C, Zanardo V. Laryngeal mask airway used as a delivery conduit for the administration of surfactant to preterm infants with respiratory distress syndrome. Biology of the Neonate 2005;87(4):217-20.

\section{van de Berg 2009}

van de Berg E, Lemmers PMA, Toet MC, Klaessens J, van Bel F. The effect of the "InSurE" procedure on cerebral oxygenation and electrical brain activity of the preterm infant. Archives of Disease in Childhood Fetal and Neonatal Edition 2010;95:F53-8.

\section{Van Marter 2000}

Van Marter LJ, Allred EN, Pagano M, Sanocka U, Parad R, Moore M, The Neonatology Committee and the Developmental Epidemiological Network. Do clinical markers of barotrauma and oxygen toxicity explain interhospital variation in rates of chronic lung disease? The Neonatology Committee for the Developmental Network. Pediatrics 2000;105(6):1194-201.

\section{Verder 1994}

Verder H, Robertson B, Greisen G, Ebbesen F, Albertsen P, Lundstrom K, Danish-Swedish Multicenter Study Group. Surfactant therapy and nasal continuous positive airway pressure for newborns with respiratory distress syndrome. Danish-Swedish Multicenter Study Group. New England Journal of Medicine 1994;331(16):1051-5.

\section{Victorin 1990}

Victorin LH, Deverajan LV, Curstedt T, Robertson B. Surfactant replacement in spontaneously breathing babies with hyaline membrane disease - a pilot study. Biology of the Neonate 1990;58(3):121-6.

\section{Wolfson 2008}

Wolfson MR, Malone DJ, Wu J, Gregory TJ, Mazela J, Shaffer TH. Aerosurf delivery during CPAP improves lung mechanics and reduces inflammation in spontaneously breathing preterm lambs. Proceeding of the 2008 Pediatric Academic Societies Annual Meeting. Honolulu, Hawaii, USA, 2008 May 2-6:P3763.19.

Yost 2000 Yost CC, Soll RF. Early versus delayed selective surfactant treatment for neonatal respiratory distress syndrome. Cochrane Database of Systematic Reviews 2000, Issue 2. [DOI: 10.1002/14651858.CD001456] 
Young 2005

Young KC, del Moral T, Claure N, Vanbuskirk S. The association between early tracheal colonization and

bronchopulmonary dysplasia. Journal of Perinatology 2005;

25(6):403-7.

\section{References to other published versions of this review}

\section{Abdel-Latif 2010}

Abdel-Latif ME, Osborn DA. Nebulised surfactant for prevention of morbidity and mortality in preterm infants with or at risk of respiratory distress syndrome (Protocol). Cochrane Database of Systematic Reviews 2010, Issue 1. [DOI: 10.1002/14651858.CD008310]

* Indicates the major publication for the study 


\title{
CHARACTERISTICS OF STUDIES
}

\section{Characteristics of included studies [ordered by study ID]}

\author{
Berggren 2000
}

\begin{tabular}{|c|c|}
\hline Methods & Multicentre RCT \\
\hline Participants & $\begin{array}{l}\text { Preterm infants who fulfilled the following enrolment criteria: } \\
\text { - corrected gestational age < } 36 \text { weeks } \\
\text { - age } 2 \text { to } 36 \text { hours } \\
\text { - clinically and radiologically diagnosed progressive } \mathrm{RDS} \\
\text { - a/A } \mathrm{pO}_{2} 0.15 \text { to } 0.22 \\
\text { - } \mathrm{FiO}_{2} \text { needed to maintain } \mathrm{SaO}_{2} 85 \% \text { to } 95 \% \text {; } \mathrm{tcpO}_{2} 6 \text { to } 8 \mathrm{kPa} \text { and } \mathrm{PaO}_{2} 7.5 \text { to } 9 \\
\mathrm{kPa} \\
\text { - No evidence lung or cardiovascular malformation } \\
\text { Infants were excluded if they did not fulfil the above criteria }\end{array}$ \\
\hline
\end{tabular}

Interventions

Nebulised surfactant group $(\mathrm{N}=17)$ : received nCPAP according to normal clinical routines. In addition, total of $480 \mathrm{mg}$ of nebulised surfactant (Curosurf) was generated via jet aerosol generator (Aiolos ${ }^{\circledR}$, Karlstad, Sweden) and given via nCPAP equipment. Surfactant was diluted to $20 \mathrm{mg} / \mathrm{mL}$ before nebulisation, and $5-\mathrm{mL}$ portions of the diluted material were aerosolised alternating with $2-\mathrm{mL}$ portions of saline. The procedure took around 3 hours

Standard protocol $(\mathrm{N}=17)$ : received nCPAP alone, without nebulised surfactant. Placebo treatment with, for instance, saline, was considered unethical and therefore not applied Indication for intubation and ventilation was not standardised, but in most cases a/A $\mathrm{pO}_{2}<0.15$ was considered as indication for intubation and ventilation

\begin{tabular}{|c|c|c|}
\hline Outcomes & \multicolumn{2}{|c|}{$\begin{array}{l}\text { Outcomes included: } \\
\text { - a/A pO at } 0,1,2,4,6 \text { and } 12 \text { hours post-randomisation } \\
\text { - air leak } \\
\text { - requirement of mechanical ventilation } \\
\text { - duration of mechanical ventilation } \\
\text { - duration of CPAP } \\
\text { - duration of oxygen supplement } \\
\text { - PDA } \\
\text { - pathological cerebral ultrasound at } 1 \text { week } \\
\text { - chronic lung disease }\end{array}$} \\
\hline Notes & \multicolumn{2}{|c|}{ Study sponsorship not reported } \\
\hline \multicolumn{3}{|l|}{ Risk of bias } \\
\hline Bias & Authors' judgement & Support for judgement \\
\hline $\begin{array}{l}\text { Random sequence generation (selection } \\
\text { bias) }\end{array}$ & Unclear risk & $\begin{array}{l}\text { Centralised randomisation. Method of sequence generation not } \\
\text { reported }\end{array}$ \\
\hline
\end{tabular}




\section{Berggren 2000 (Continued)}

\begin{tabular}{l|l|l}
\hline Allocation concealment (selection bias) & Unclear risk & $\begin{array}{l}\text { Allocation using sealed envelopes kept on neonatal ward. Num- } \\
\text { bering and opaqueness not reported }\end{array}$ \\
\hline $\begin{array}{l}\text { Blinding of participants and personnel } \\
\text { (performance bias) } \\
\text { All outcomes }\end{array}$ & High risk & No placebo used \\
\hline $\begin{array}{l}\text { Blinding of outcome assessment (detection } \\
\text { bias) } \\
\text { All outcomes }\end{array}$ & High risk & No placebo used, blinding of outcome assessment not reported \\
\hline $\begin{array}{l}\text { Incomplete outcome data (attrition bias) } \\
\text { All outcomes }\end{array}$ & Low risk & $\begin{array}{l}2 / 34(6 \%) \text { infants excluded (1 in each group) post allocation as } \\
\text { not meeting enrolment criteria }\end{array}$ \\
\hline Selective reporting (reporting bias) & Unclear risk & $\begin{array}{l}\text { Primary outcomes not specific - safety and need for mechanical } \\
\text { ventilation' }\end{array}$ \\
\hline Other bias & High risk & $\begin{array}{l}\text { Indication for intubation and ventilation was not standardised, } \\
\text { but in most cases a/A pO } 2<0.15 \text { was considered as indication } \\
\text { for intubation and ventilation. pH was lower in the treatment } \\
\text { group compared to controls at randomisation }(7.29 \text { versus 7.32; } \\
\text { P < 0.019) }\end{array}$ \\
\hline
\end{tabular}

a/A $\mathrm{pO}_{2}$ : arterio/alveolar oxygen tension ratio; CLD: chronic lung disease; nCPAP: nasal continuous positive airway pressure; PDA: patent ductus arteriosus; RCT: randomised controlled trial; RDS: respiratory distress syndrome

Characteristics of excluded studies [ordered by study ID]

\begin{tabular}{ll}
\hline Study & Reason for exclusion \\
\hline Arroe 1998 & Observational non-randomised and non-controlled study \\
\hline Finer 2010 & Observational non-randomised and non-controlled study \\
\hline Jorch 1997 & Observational non-randomised and non-controlled study \\
\hline Pearson 2005 & Observational non-randomised and non-controlled study involving infant-simulator \\
\hline
\end{tabular}


DATA AND ANALYSES

Comparison 1. Treatment of RDS with nebulised surfactant versus no treatment

\begin{tabular}{lcclc} 
Outcome or subgroup title & $\begin{array}{c}\text { No. of } \\
\text { studies }\end{array}$ & $\begin{array}{c}\text { No. of } \\
\text { participants }\end{array}$ & Statistical method & Effect size \\
\hline 1 Chronic lung disease & 1 & 32 & Risk Ratio (M-H, Fixed, 95\% CI) & $5.0[0.26,96.59]$ \\
2 Mechanical ventilation & 1 & 32 & Risk Ratio (M-H, Fixed, 95\% CI) & $1.2[0.46,3.15]$ \\
3 Air leak & 1 & 32 & Risk Ratio (M-H, Fixed, 95\% CI) & $1.0[0.30,3.32]$ \\
4 Patent ductus arteriosus & 1 & 32 & Risk Ratio (M-H, Fixed, 95\% CI) & $1.5[0.29,7.81]$ \\
5 Pathological cerebral ultrasound & 1 & 26 & Risk Ratio (M-H, Fixed, 95\% CI) & $0.29[0.01,6.50]$ \\
$\quad$ & & & & \\
\hline
\end{tabular}

\section{Analysis I.I. Comparison I Treatment of RDS with nebulised surfactant versus no treatment, Outcome Chronic lung disease.}

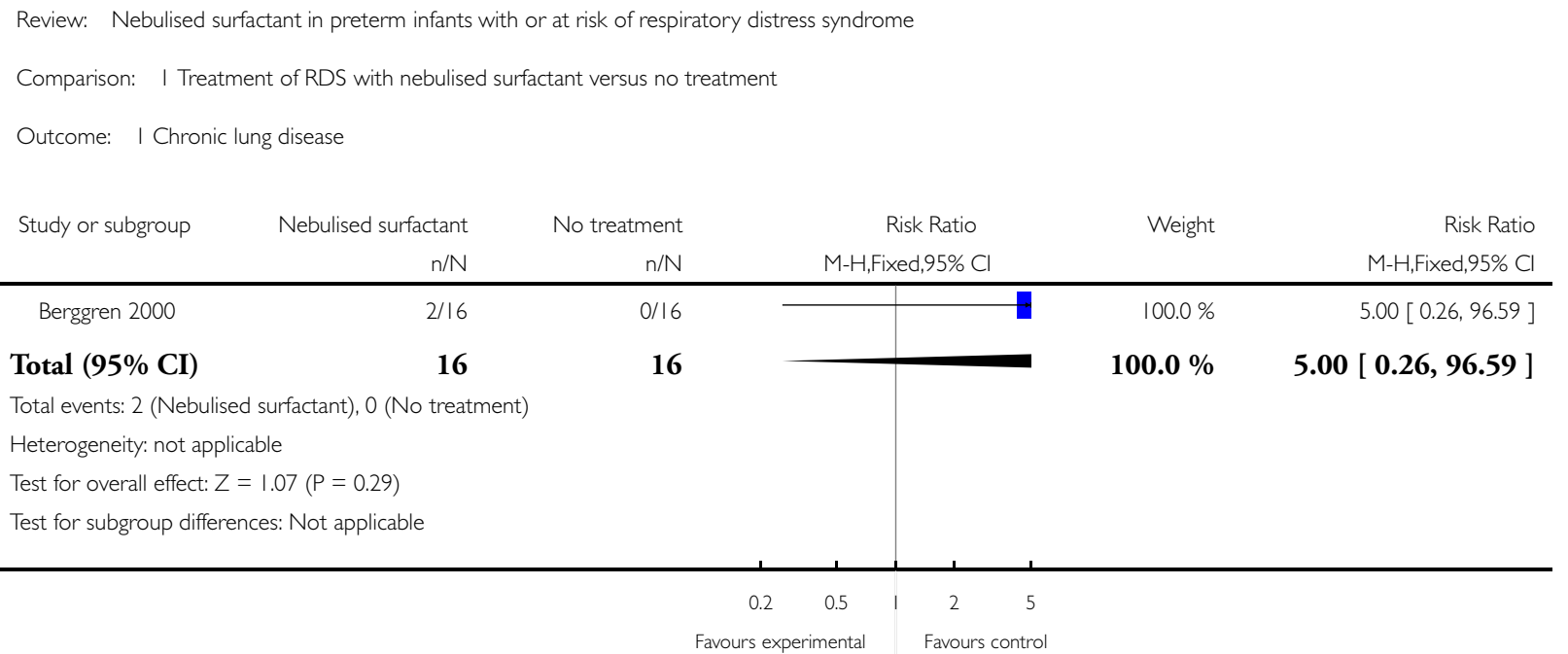


Analysis I.2. Comparison I Treatment of RDS with nebulised surfactant versus no treatment, Outcome 2 Mechanical ventilation.

Review: Nebulised surfactant in preterm infants with or at risk of respiratory distress syndrome

Comparison: I Treatment of RDS with nebulised surfactant versus no treatment

Outcome: 2 Mechanical ventilation

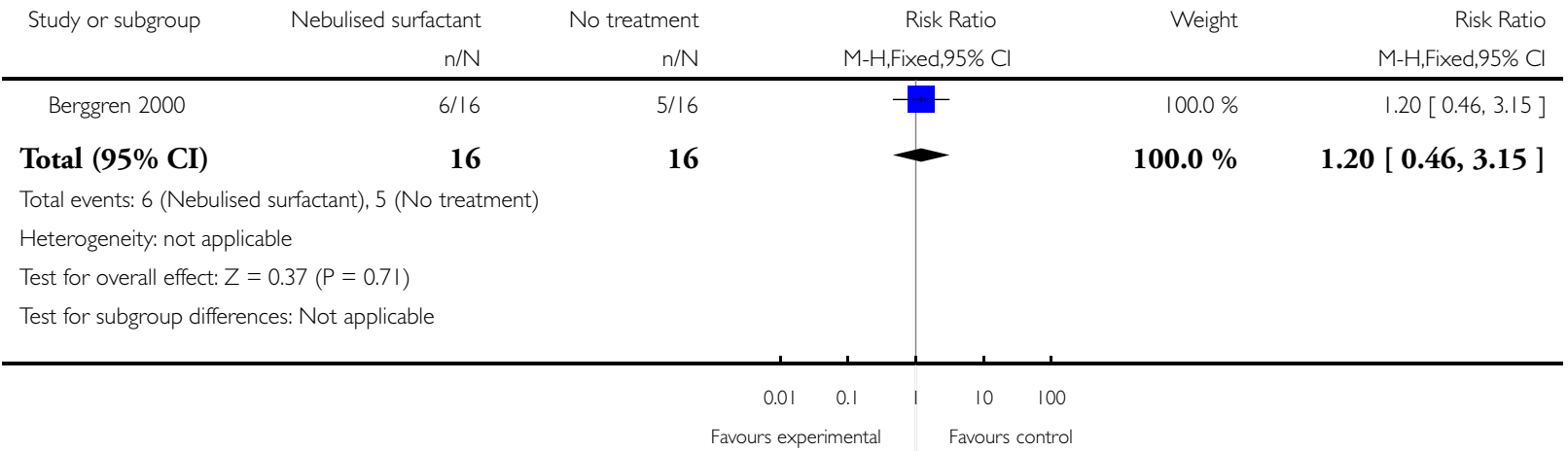

\section{Analysis I.3. Comparison I Treatment of RDS with nebulised surfactant versus no treatment, Outcome 3} Air leak.

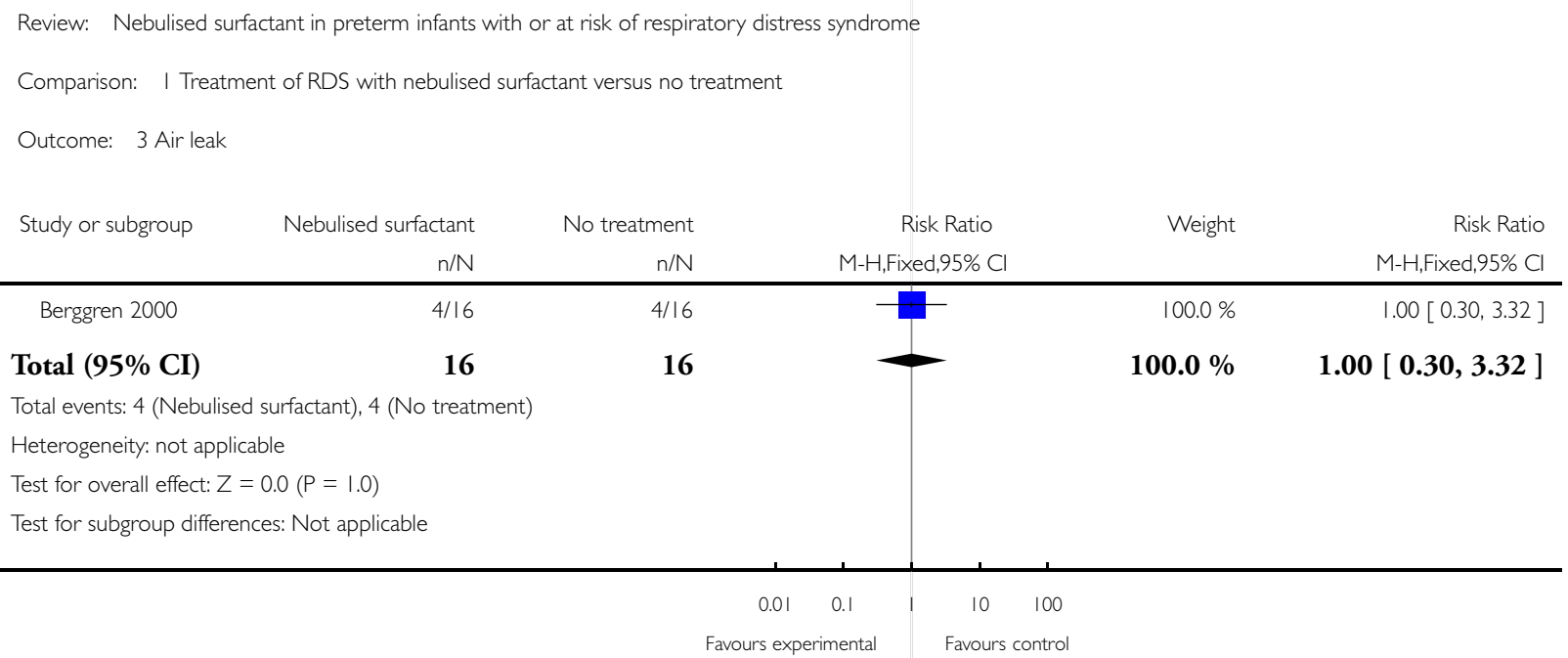


Analysis I.4. Comparison I Treatment of RDS with nebulised surfactant versus no treatment, Outcome 4 Patent ductus arteriosus.

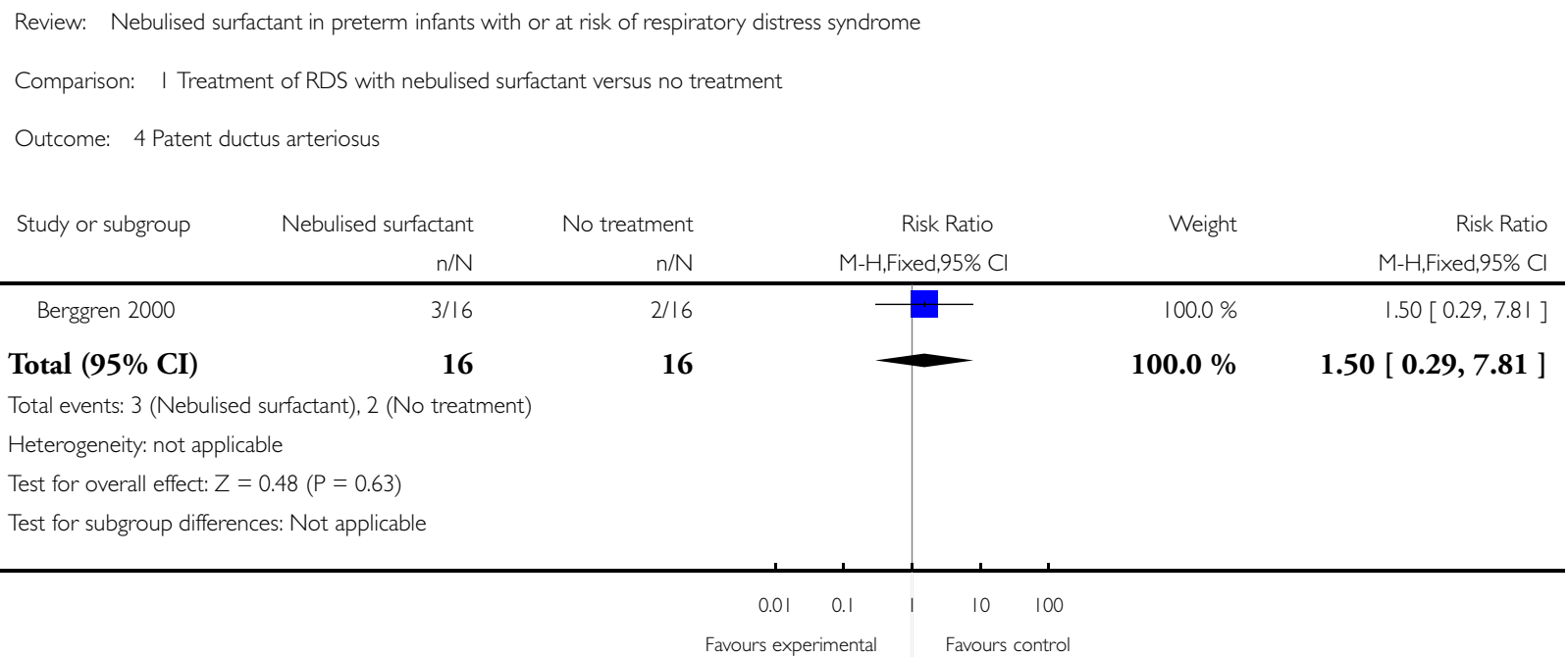

\section{Analysis 1.5. Comparison I Treatment of RDS with nebulised surfactant versus no treatment, Outcome 5 Pathological cerebral ultrasound at I week.}

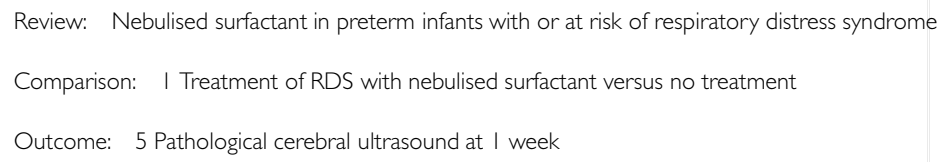

\begin{tabular}{|c|c|c|c|c|c|}
\hline \multirow[t]{2}{*}{ Study or subgroup } & Nebulised surfactant & No treatment & Risk Ratio & Weight & Risk Ratio \\
\hline & $\mathrm{n} / \mathrm{N}$ & $\mathrm{n} / \mathrm{N}$ & M-H,Fixed,95\% Cl & & M-H,Fixed,95\% Cl \\
\hline Berggren 2000 & $0 / 14$ & $1 / 12$ & 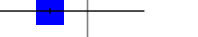 & $100.0 \%$ & $0.29[0.01,6.50]$ \\
\hline Total $(95 \%$ CI $)$ & 14 & 12 & & $100.0 \%$ & $0.29[0.01,6.50]$ \\
\hline
\end{tabular}

Total events: 0 (Nebulised surfactant), I (No treatment)

Heterogeneity: not applicable

Test for overall effect: $Z=0.78(P=0.43)$

Test for subgroup differences: Not applicable 


\section{A P P E N D I C E S}

\section{Appendix I. MEDLINE search strategy}

\#1 exp pregnancy

\#2 exp infant premature

\#3 exp infant newborn

\#4 exp obstetric labor premature

\#5 exp premature birth

\#6 pregnan*.mp OR prematur*.mp OR preterm.mp OR neonat*.mp OR infant*.mp OR newborn.mp

\#7 \#1 OR \#2 OR \#3 OR \#4 OR \#5 OR \#6

$\# 8$ aerosoli*.mp

\#9 nebuli*.mp

\#10 \#8 OR \#9

\#11 exp pulmonary surfactants

\#12 surfactant*.mp OR Beractant.mp OR Poractant.mp OR Curosurf.mp OR Survanta.mp OR Exosurf.mp OR Lucinactant.mp OR Aerosurf.mp

\#13 \#11 OR \#12

\#14 \#7 AND \#10 AND \#13

\section{H I S T O R Y}

Protocol first published: Issue 1, 2010

Review first published: Issue 10, 2012

\section{CONTRIBUTIONSOFAUTHORS}

Mohamed E Abdel-Latif wrote the first draft of the review and revised subsequent drafts; assessed study eligibility, carried out data extraction, and entered data.

David A Osborn assessed study eligibility, entered data, carried out data extraction, checked data, commented and revised subsequent drafts of the review.

\section{DECLARATIONSOF INTEREST}

None known.

\section{SOURCES OF SUPPORT}




\section{Internal sources}

- No sources of support supplied

\section{External sources}

- Australian Satellite of the Cochrane Neonatal Review Group, Australia.

- Eunice Kennedy Shriver National Institute of Child Health and Human Development National Institutes of Health, Department of Health and Human Services, USA.

Editorial support of the Cochrane Neonatal Review Group has been funded with Federal funds from the Eunice Kennedy Shriver National Institute of Child Health and Human Development National Institutes of Health, Department of Health and Human Services, USA, under Contract No. HHSN275201100016C

\section{DIFFERENCES BETWEEN PROTOCOLANDREVIEW}

None.

\section{NDEX TERMS}

\section{Medical Subject Headings (MeSH)}

Administration, Inhalation; Biological Agents [*administration \& dosage]; Infant, Newborn; Infant, Premature; Nebulizers and Vaporizers; Phospholipids [*administration \& dosage]; Pulmonary Surfactants [*administration \& dosage]; Respiratory Distress Syndrome, Newborn [*drug therapy]

\section{MeSH check words}

Humans 